\title{
Evaluation of Molecularly Imprinted Thin Films for Ephedrine Recognition
}

\author{
ELENA B. STOICA ${ }^{1 \#}$, ANA-M. GAVRILA ${ }^{1 \#}$, CATHERINE BRANGER ${ }^{2}$, HUGUES BRISSET $^{2}$, ANTON V. DYSHLYUK ${ }^{3}$, \\ OLEG B. VITRIK ${ }^{3}$, HORIA IOVU ${ }^{4}$, ANDREEA MIRON ${ }^{1}$, ANDREI SARBU ${ }^{1 *}$, TANTA-V. IORDACHE ${ }^{1 *}$ \\ ${ }^{1}$ National Institute for Research\&Development in Chemistry and Petrochemistry ICECHIM, Advanced Polymer Materials and Polymer Recycling \\ Group, 202 Splaiul Independentei, 060021,Bucharest, Romania \\ ${ }^{2}$ Laboratoire MAPIEM of Toulon University, SeaTech, Bât. X, Avenue de l'Université, 83130 LA GARDE - FRANCE \\ ${ }^{3}$ Institute of Automation and Control Processes (Far Eastern Branch of Russian Academy of Sciences) and Far Eastern Federal University, 5 Radio \\ Str., Vladivostok, Russia \\ ${ }^{4}$ University Politehnica of Bucharest, Faculty of Applied Chemistry and Materials Science, Advanced Polymer Materials Group, 1-7 Polizu, \\ 011061, Bucharest, Romania
}

Ephedrine is an illicit drug, classified as precursor for methamphetamine, which is also used as stimulant, appetite suppressant, decongestant or asthma. In this study, novel molecularly imprinted polymer (MIP) films were prepared by sol-gel derived techniques, using $\mathrm{N}$-(2-aminoethyl)-3-aminopropyltrimethoxysilane as functional monomer, to recognize ephedrine from aqueous solutions. The films were obtained by air-spraying the precursor solutions, with various concentrations of monomer and template, on glass supports. Infrared, thermogravimetry, ellipsometry, optic and atomic force microscopy analyzes of films provided information regarding the effect of molecular imprinting upon the physical properties of films. Further on, batch rebinding evaluation indicated that thinner films present high affinity for ephedrine, resulting in 6.2 imprinting factor after 15 minutes of contact, which attests the ability of the novel MIP films to recognize and rebind ephedrine.

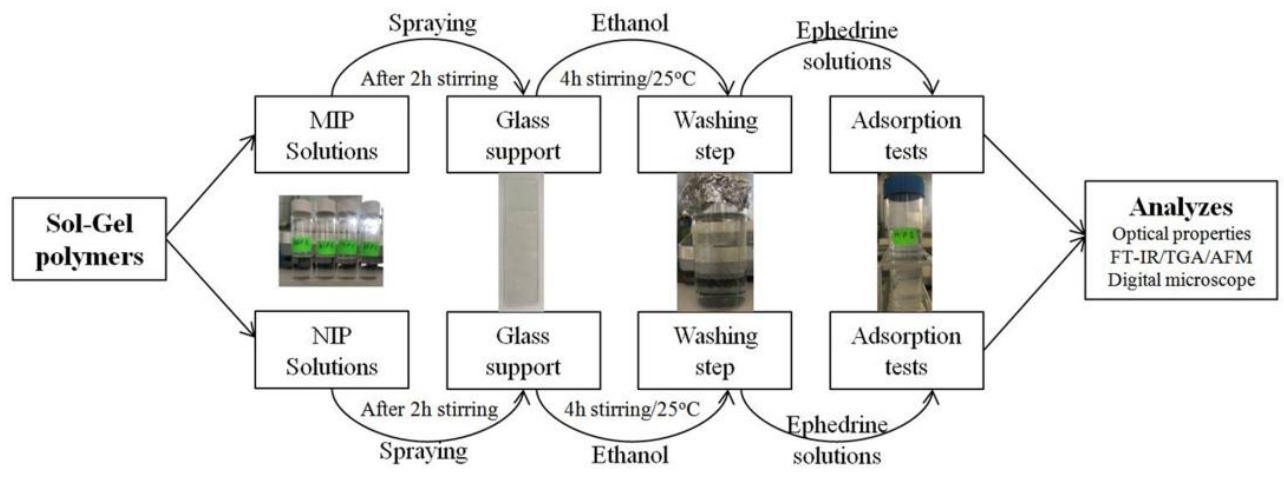

(a)
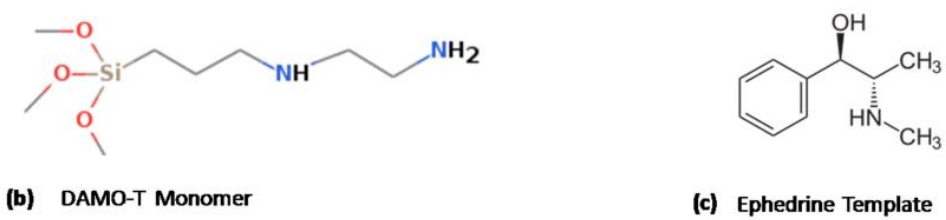

(b) DAMO-T Monome

(c) Ephedrine Template

Graphical Abstract: Schematic preparation of ephedrine-MIP/NIP films (a), the structure of the functional monomer DAMO-T (b) and the structure of ephedrine (c)

Keywords: molecularly imprinted polymers; thin films; sol-gel deposition; ephedrine; specificity; optical properties

Nowadays, the abuse of illicit drugs (like ephedrine, methamphetamine, LSD, cocaine) has become one of the biggest problems of the world. The illicit drugs affect people health, directly (by oral, intranasal, injection or inhalation) or indirectly (from the environment - as a result of human body metabolism after consumption, and/or accidentally or deliberately following inappropriate storage, or by waste discharged from illegal synthesis laboratories) [1-3]. Due to this combination, the demand of detection devices for the most used drugs has increased considerably in the last years. For 
instance, ephedrine is a sympathomimetic amine, an illicit drug which is also used as a medicine - concentration aid, stimulant, appetite suppressant, decongestant, asthma [4-6]. The molecular structure of ephedrine is close to that of methamphetamine, being classified as its precursor. Methamphetamine can be obtained from ephedrine or pseudoephedrine and hydrionic acid, or in situ [7-10]. The molecular formula of ephedrine is $\mathrm{C}_{10} \mathrm{H}_{15} \mathrm{NO}$ and the molecular weight is $165 \mathrm{~g} / \mathrm{mol}$. It is presented as white microcrystalline powder/granules/pieces, odorless. The boiling point is $255^{\circ} \mathrm{C}$. It is soluble in water, ethanol, ether, benzene and chloroform [11]. For this particular drug, the detection is made using chromatography-mass spectrometry [12, 13], gas chromatography-mass spectrometry [14, 15], Fourier transform infrared (FT-IR), high performance liquid chromatography (HPLC) or nuclear magnetic resonance (NMR), etc. [16]. However, the present methods are limited to high response time, expensive manufacturing costs, lack of portability and so on. Therefore, sensors are becoming more attractive for such applications. Due to many advantages, like low manufacturing costs, real-time analysis, selectivity, short response time and small dimensions [17, 18], sensors are used nowadays for various purposes targeting population safety, industrial hygiene, product quality, emission monitoring, clinical diagnosis, environmental monitoring, etc. [19].

A sensor is a device that converts the chemical/physical changes of a material (i.e. the information) into measurable analytical signals. The information can be derived from a chemical reaction or from a change of the physical property of the system when contacted with the analyte. The main elements of sensor devices are the receptor and the transducer. The information generated by the receptor as a form of energy is transformed into a measurable signal by the active transducer (which can be an electric tension, electric/light intensity, frequency, and so on, as function of the method of energy conversion) $[20,21]$ and further displayed using appropriate detectors depending on the nature of the output signal (e.g. potentiostats, oscilloscopes, ellipsometers or spectroscopes etc.). Since various types of versatile transducers were developed in the last decades [22-27], and are now commercially available [28, 29], in this study the attention was focused towards developing receptors with the ability to recognize and rebind ephedrine. In this respect, molecular imprinting and sol-gel technology were combined in order to deliver a performant thin film, which can be further used as recognition element for preparing sensors.

Molecular imprinting is a technique used to obtain artificial receptors which are able to recognize with high precision and rebind various small molecules or macromolecules [30-38]. Molecularly imprinted polymer (MIP) films are now used to obtain a wide range of sensors $[39,40]$ due to their advantages like low cost, high performance in organic solvents, selectivity, affinity for the template, ease of preparation, and so on [41-43]. In order to obtain imprinted polymers, the formation of a polymerizable complex between the functional monomer/s and the template is extremely important. Afterward, the polymerization of the obtained complex in the presence of a cross-linker stiffens the polymer structure and, finally, the following template removal leads to binding sites that are complementary in size, shape, and functional group with the template molecule [44].

Obtaining of sol-gel derived MIP films involves two steps, i.e. deposition of precursor solution (where hydrolysis of silane leads to the formation of silanol reactive groups) followed by maturation of film (where polycondensation of the silanol reactive groups occurs with the formation of polysiloxane rigid networks [45-47]. MIP films obtained by sol-gel deposition feature good selectivity, low cost and stability at re-use [48], which is why are used in a wide range of applications, like ceramic synthesis, thin films and sensors. One of the most important advantages of these materials refers to nano-scalability in terms of film thickness. Plus, the nano-scaled thickness together with the film's transparency and the positive response in the visible region makes such MIP films potentially viable for developing optical sensors [49, 50]. Hence, the preparation of the molecularly imprinted thin films for ephedrine recognition, using a sol-gel derived method, would be the main novelty of this study.

\section{Experimental part}

\section{Materials and methods}

The monomer, N-(2-aminoethyl)-3-aminopropyltrimethoxysilane (DAMO-T), 97\% was purchased from Sigma Aldrich (St. Louis, MO, USA) and used as was received. The template, ephedrine hydrochloride $50 \mathrm{mg} / \mathrm{mL}$ was purchased from Zentiva ( $U$ Kabelovny, Prague, $C Z$ ) and used as was received. Ethanol, 99.5\%, was purchased from ChimReactiv (Ion Creanga, NT, RO) and ammonium hydroxide, 25\%, from Chimopoar (Bd. Pallady Theodor, B, RO). Distillate water was obtained in our laboratory.

The films deposited on glass substrates were analysed using the spectro-eliposometric method. All measurements were performed with UV-Vis-NIR Ellipsometer VASE® (from J.A. Woollam Co, Inc.) in the 190 - 1000 nm wavelength range at $70^{\circ} \mathrm{AOI}$ with a $10 \mathrm{~nm}$ step and 20 scans/ measurement (microspot). 
Microscopy and topography of films was assessed using digital microscopy - Hirox RH-2000 Digital, atomic force microscopy in non-contact mode - NT-MDT NTEGRA Probe NanoLaboratory system (NT-MDT NSG01 cantilever with tip radius of $10 \mathrm{~nm}$ ) and scanning electron microscopy - Zeiss Supra 40VP.

The structure analysis was carried out using Nicolet iS50 FT-IR device with ATR - SMART iTR (Termo SCIENTIFIC) and thermal analysis was performed using TA Instrument SDT Q600 Thermo-Gravimetric Device.

For batch rebinding experiments Thermo Nicolette UV-VIS Spectrometer was used in order to determine the adsorption of ephedrine at the specific wavelength, $\lambda=257 \mathrm{~nm}$.

\section{Preparation of film precursor solutions and film deposition}

The films were synthesized by a sol-gel derived technique in basic conditions, according to a similar recipe developed by Florea et al. [51], which involved the hydrolysis of methoxy groups of the monomer, followed by their condensation for obtaining the rigid polymer network.

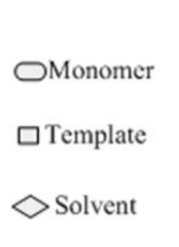

(a)

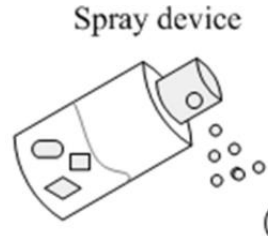

Glass substrate

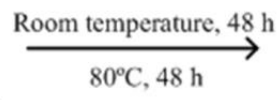

$80^{\circ} \mathrm{C}, 48 \mathrm{~h}$

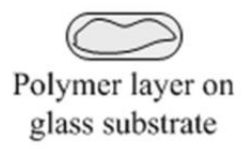

Polymer layer on
glass substrate

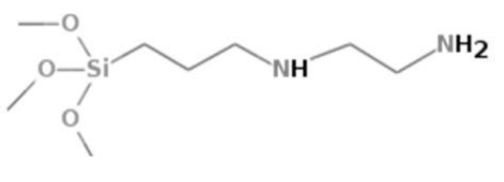

(b) DAMO-T Monomer

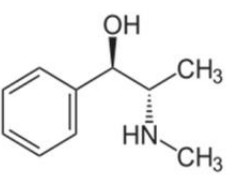

(c) Ephedrine Template

Fig. 1. Preparation of ephedrine-MIP/NIP films (a), the structure of the functional monomer DAMO-T (b) and the structure of ephedrine (c)

For each sample, two solutions were prepared as follows: solutions A, which consists in dissolving in ethanol the monomer and the template, i.e. ephedrine hydrochloride, and solution B obtained from ammonium hydroxide and water. After the two solutions were homogenized separately, solution A was added over B to yield the MIP film precursor solution. After $2 \mathrm{~h}$ of mechanical stirring the precursor was casted on glass substrates by air-spraying (Figure 1). The same procedure was used for obtaining the control films (NIPs) but without adding the template. Using this technique two film series with various thicknesses, namely MIP C/NIP C and MIP D/NIP D pairs (Table 1), were obtained by dilution of solution A. After deposition, the films were maturated at room temperature for 48 hours, then for another 48 hours at $80^{\circ} \mathrm{C}$ in an oven.

Table 1

RECIPES FOR THE PREPARATION OF MIP/NIP PRECURSOR SOLUTIONS

\begin{tabular}{llllll}
\hline & Substance [mmoles] & MIP C & NIP C & MIP D & NIP D \\
\hline \multirow{3}{*}{ Solution A } & DAMO-T Monomer & 0.7 & 0.7 & 0.7 & 0.7 \\
& EtOH Solvent & 17 & 17 & 34 & 34 \\
& Ephedrine Template & 0.07 & 0 & 0.07 & 0 \\
\multirow{2}{*}{ Solution B } & $\mathrm{NH}_{4} \mathrm{OH}$ Solvent & 12.5 & 12.5 & 27.7 & 27.7 \\
& $\mathrm{H}_{2} \mathrm{O}$ Solvent & 14 & 14 & 28 & 28 \\
\hline
\end{tabular}

All MIP films were washed with ethanol to extract the ephedrine and to remove the unreacted monomer. In this step, the films were immersed in $100 \mathrm{~mL}$ of ethanol and placed in the ultrasonic bath for 4 hours at room temperature. To reduce errors, the same procedure was applied to the NIPs, as well.

\section{Rebinding capacity and imprinting factor of films}

The adsorption capacity is one of the most important characteristics of MIP sensitive films. Depending of this property the sensor is capable or not to recognize the template, in this case ephedrine. Therefore, batch rebinding measurements are highly useful to validate the specificity of MIP films by measuring the adsorbed amount of ephedrine relative to the NIP films. In this respect, dried MIP and NIP films were immersed in $40 \mathrm{~mL}$ of aqueous solution containing 2.74 mmoles of 
ephedrine/L. The quantification method referred, in this case, to measuring the initial and final concentration of the feed aqueous solutions (i.e. before and after contact with the films) using a UV-Vis Spectrophotometer. The specific parameters used to determine the adsorption performance were calculated using the following equations:

Where:

$$
Q=\frac{\left(c_{N, i}-c_{N, f}\right) \cdot V_{s}}{m_{p}}
$$

- $\quad Q$ is the binding capacity of films, (g of ephedrine/ $\mathrm{g}$ of film);

- $\quad c_{N, i}(\mathrm{~g} / \mathrm{L})$ and $c_{N, f}(\mathrm{~g} / \mathrm{L})$ are the initial and final concentrations of ephedrine in solutions;

- $\quad V_{s}(\mathrm{~L})$ is the initial volume of the solution;

- $\quad m_{p}(\mathrm{~g})$ is the quantity of the polymer layer.

$$
F=\frac{Q_{M I P}}{Q_{N I P}}
$$

Where:

- $\quad F$ is the imprinting factor, which quantifies the specificity of adsorption;

- $\quad Q_{M I P}$ (g ephedrine/g of MIP) is the adsorption capacity of MIP;

- $\quad Q_{N I P}$ (g ephedrine/g of NIP) is the adsorption capacity of NIP.

Calibration was performed in the $5.48 \mathrm{mmoles} / \mathrm{L}-0.137 \mathrm{mmol} / \mathrm{L}$ ephedrine concentration range. The regression equation, Eq. (3), used to calculate the concentration of ephedrine was determined at the specific wavelength, $\lambda=257 \mathrm{~nm}$ with a regression coefficient, $r=0.982$.

$$
c_{N}=\frac{A-0.014}{167.2}
$$

Where:

- $\quad A$ is the sample absorbance at $\lambda=257 \mathrm{~nm}$;

- $\quad c_{N}(\mathrm{~g} / \mathrm{L})$ is the concentrations of ephedrine in the analyzed sample;

\section{Results and discussions}

\section{Thickness assessment and optical proprieties}

According to the synthesis recipes of films that use two different concentrations for the precursor solution, the final films after maturation should present either nano- or micron-sized thickness. Ellipsometry is one of the fewest methods to allow proper evaluation of thickness for transparent films. In this respect, ellipsometric data were fitted according to the Cauchy Model for transparent materials (given in Table 2), which allowed thickness evaluation of films. Thickness differences were observed for both the MIP D/ NIP D and MIP C/NIP C films as summarized in Table 2.

Table 2

FILMS THICKNESS DETERMINED BY ELLIPSOMETRY USING THE CAUCHY MODEL

\begin{tabular}{|c|ccc|}
\hline \multicolumn{1}{c}{ Cauchy Model } & Sample & $\mathbf{d}_{\text {layer }}[\mathbf{n m}]$ & $\begin{array}{l}\text { MSE*(mean } \\
\text { square error) }\end{array}$ \\
\hline Rugosity & & & \\
Cauchy - Thin & NIP D & 194.77 & 0.76 \\
film & MIP D & 201.29 & 1.04 \\
& NIP C & 5126.18 & 0.96 \\
& MIP C & 3811.13 & 0.63 \\
\hline Glass - substrate & & & \\
\hline
\end{tabular}

Figure 2 reveals the refractive index variation of the analyzed films obtained from the ellipsometric data modelling. As shown in Figure 2a and b, the refractive indexes were higher for the MIP films due to ephedrine presence in the films structure. Hence, both MIP film types presented optical response for the target molecule regardless of thickness. The refractive index difference, $\Delta n$, in the $600-1000 \mathrm{~nm}$ range (visible range) between MIP C and NIP C varied from 0.004 to 0.005 , while for MIP D and NIP D was constant, $\Delta n=0.003$. This latter result indicated again that thinner films are more homogenous. 
Further on, in Figure 2c and d, the transmittance profiles of MIP and NIP film pairs was evaluated. Herein, the glass substrate presented the highest transmission, over 92\%, across the 350-900 $\mathrm{nm}$ wavelength range. Transmission of films was lower than that of glass alone, maximum being attained by NIP D with over $87 \% \mathrm{~T}$, which is explainable due to its low thickness. Yet, the MIP D transparency was even lower, compared to that of MIP C and NIP C, indicating the formation of different networks due to monomer-template auto-assembly.
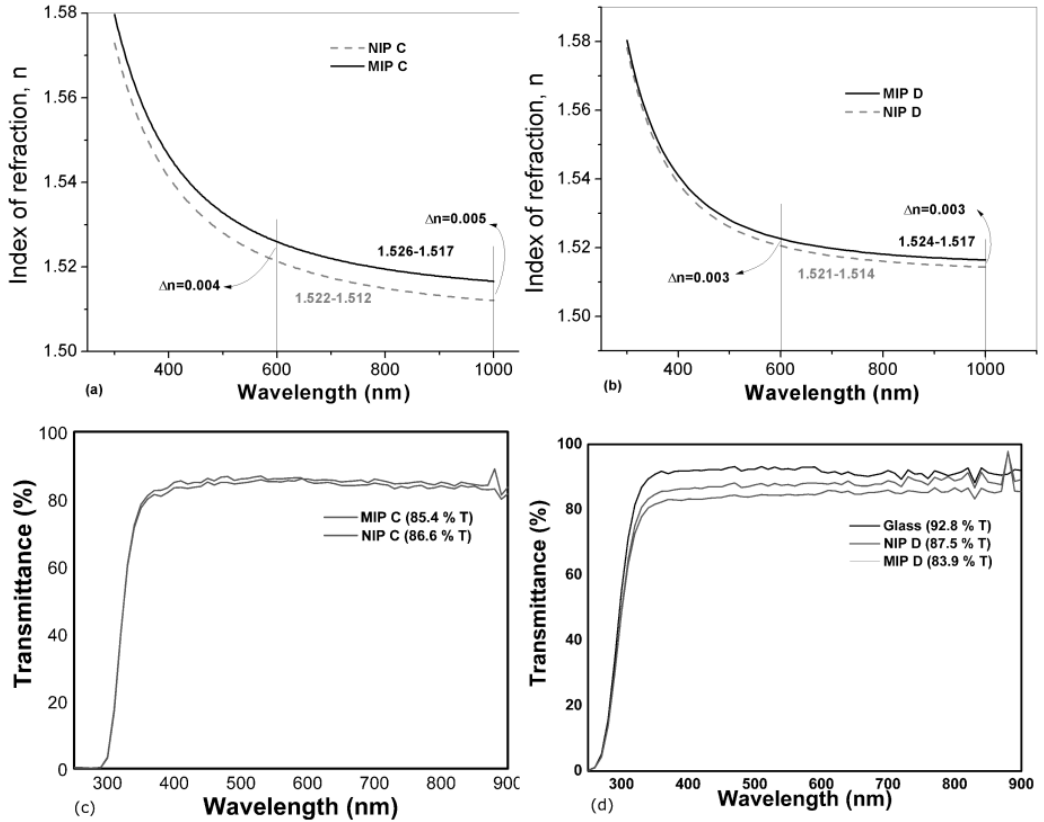

Fig. 2. Refractive index variation in the $250-1000 \mathrm{~nm}$ wavelength range, for:

NIP C/ MIP C films (a), and NIP D/ MIP D films (b); Transmittance profiles, in the 250-900 nm wavelength range, for: NIP C/ NIP D films (c), and MIP C/ MIP D films (d)

\section{FT-IR analysis}

All the films were evaluated by FT-IR and their spectra are shown in Figure 3. The characteristic band for $-\mathrm{OH}$ stretching (terminal groups of the organosilica network) was present in the range of $3260-3280 \mathrm{~cm}^{-1}$. Methylene groups from the DAMO-T monomer were spotted around $2930 \mathrm{~cm}^{-1}$. The stretching of Si-O-Si backbone was noticed in the $850-$ $1108 \mathrm{~cm}^{-1}$ range. Deformation vibrations of the primary $\left(-\mathrm{NH}_{2}-\right)$ and secondary (-NH-) amines were observed around 1650 $\mathrm{cm}^{-1}$ and $1470 \mathrm{~cm}^{-1}$, respectively, and can be attributed to both the template (ephedrine) and the monomer. The presence of ephedrine in the MIP films (Figure3a and c) was attested by the shift of the NH2 band with around $10 \mathrm{~nm}$; this being the functional group in the monomer/polymer responsible for template interactions via hydrogen bonds.
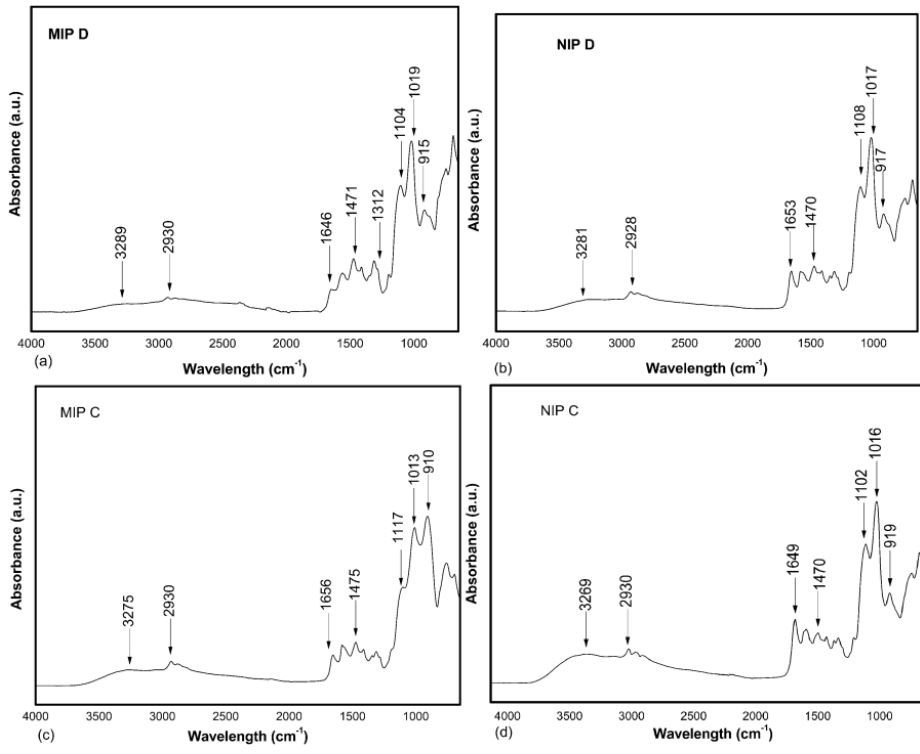

Fig. 3. FT-IR spectra of films: (a) MIP D, (b) NIP D, (c) MIP C, (d) NIP C. 


\section{TGA analyses}

For determining the thermal behavior, the MIP and NIP films were scratched off the glass substrate and analyzed by thermo-gravimetry (thermograms and derivatives depict in Figure 4.a-d). In the first interval, the mass loss of all films was associated with the loss of water and ethanol. In the 200-300 ${ }^{\circ} \mathrm{C}$ range, thermal degradation of ephedrine occurred (attaining a maximum at $220^{\circ} \mathrm{C}$ ), as observed from the thermogram of MIP C and MIP D (Figure 4.a and c). The next range valid for all films, $300-500{ }^{\circ} \mathrm{C}$, can be attributed to degradation/fragmentation of the pendant groups (i.e. amino, amino-ethyl, amino-methyl, methyl and ethyl fragment types), and the last degradation step, between $500-800{ }^{\circ} \mathrm{C}$, represented the degradation of the polymer backbone [51]. At $800^{\circ} \mathrm{C}$ all films registered high amounts of residue, which also confirmed the good thermal stability of the films. Here it can be mentioned that the residue was higher for MIP D film (Figure 4.a), which indicated a more discrete auto-assembly between the monomer and the template at lower concentrations of precursors. Concluding, the monomer-template auto-assembly in the imprinting stage has led to more homogenous and compact structure of films.
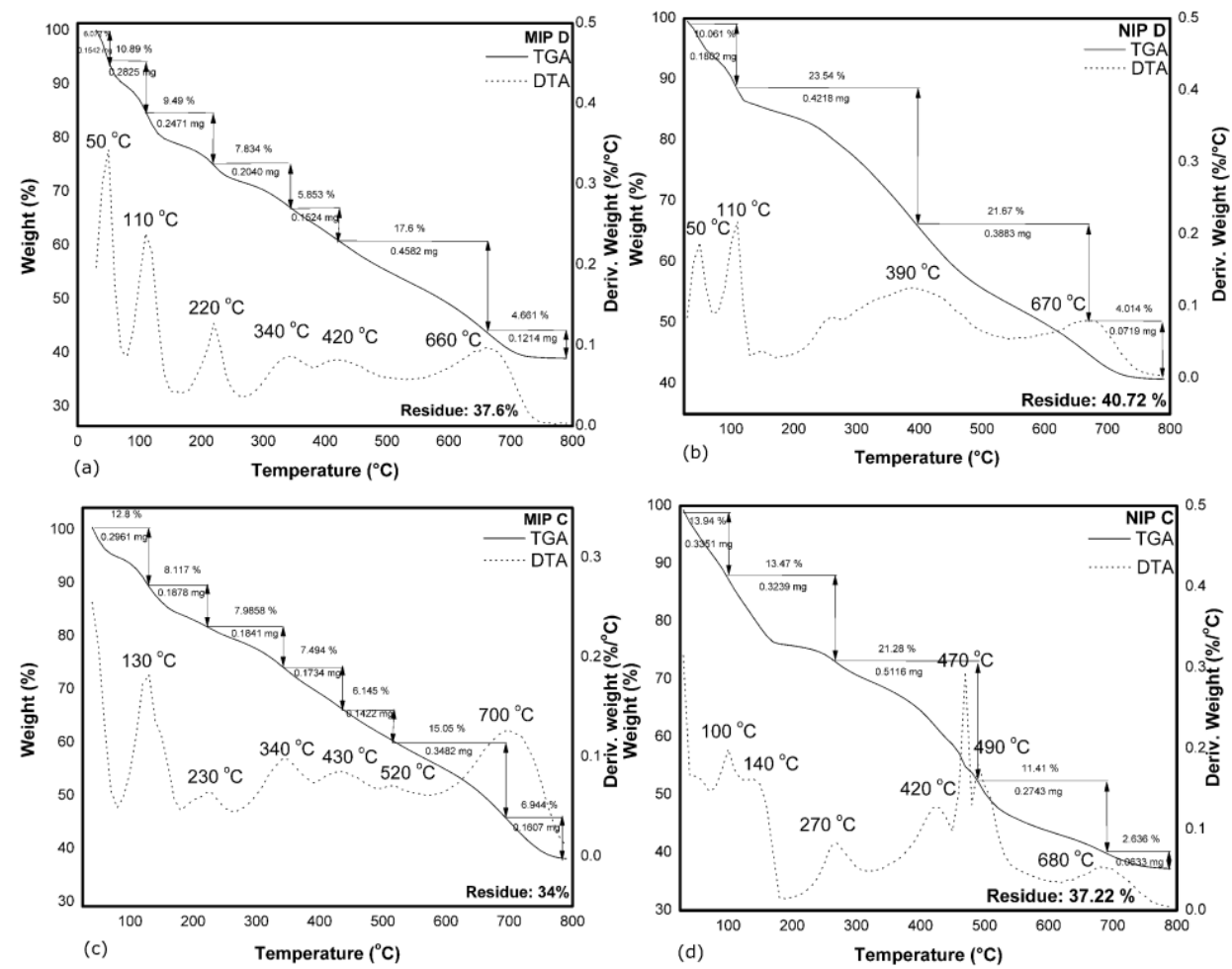

Fig. 4. Thermograms (TG) and derivatives of films (DTG): (a) MIP D, (b) NIP D, (c) MIP C, (d) NIP C.

\section{Microscopy analysis}

Besides the recognition properties for ephedrine, the sensor elements should also be continuous with no cracks (to have homogenous properties on bulk) and also to present a high surface/contact area to enhance the sensitivity of the future sensor. As a result, the films morphology was analyzed using digital, atomic force and electron microscopy. For discrete analysis of morphology on thin films SEM was very much suited. AFM was used to calculate changes in roughness and surface area variations due to differences in films deposition. The optical microscopy was also used to observe if the films were homogenous on larger surfaces after maturation; it is important for sensors applications to have a homogenous film with no cracks as the electrical properties and reproducibility are very much influenced by this factor. As it can be observed from the digital snapshots, MIP D and NIP D films (Figure 5.c and d) present less asperities and bubbles than MIP C and NIP C (Figure 5.a and b). Hence, the thin films were indeed more homogeneous as revealed by the thermal analyses, as well. 


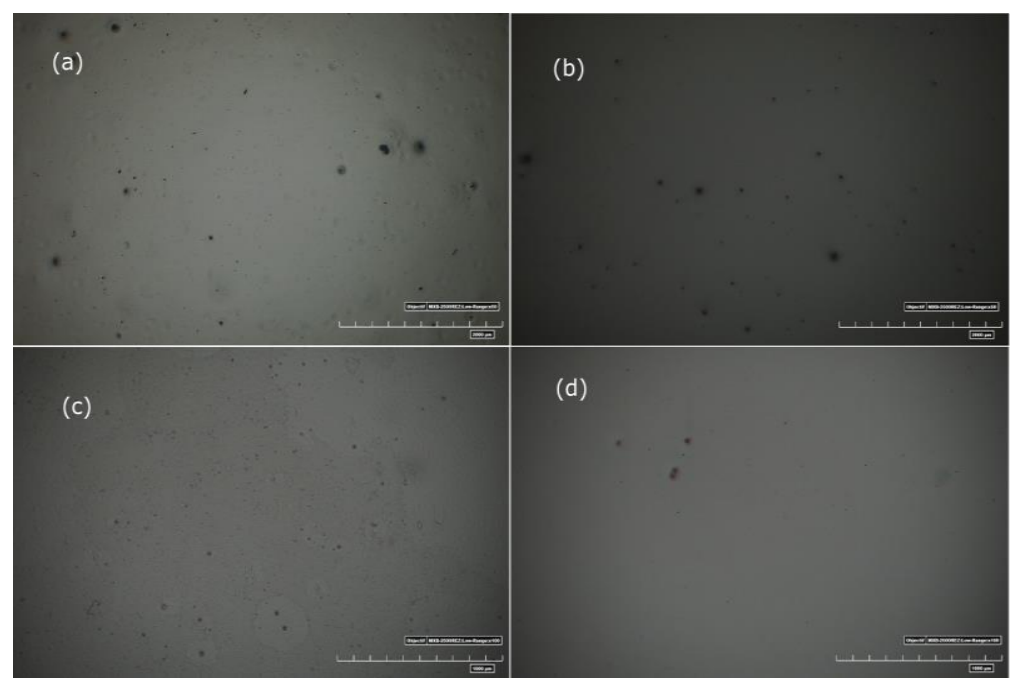

Fig. 5. Digital microscope snapshots of films: (a) MIP C, (b) NIP C, (c) MIP D, (d) NIP D.
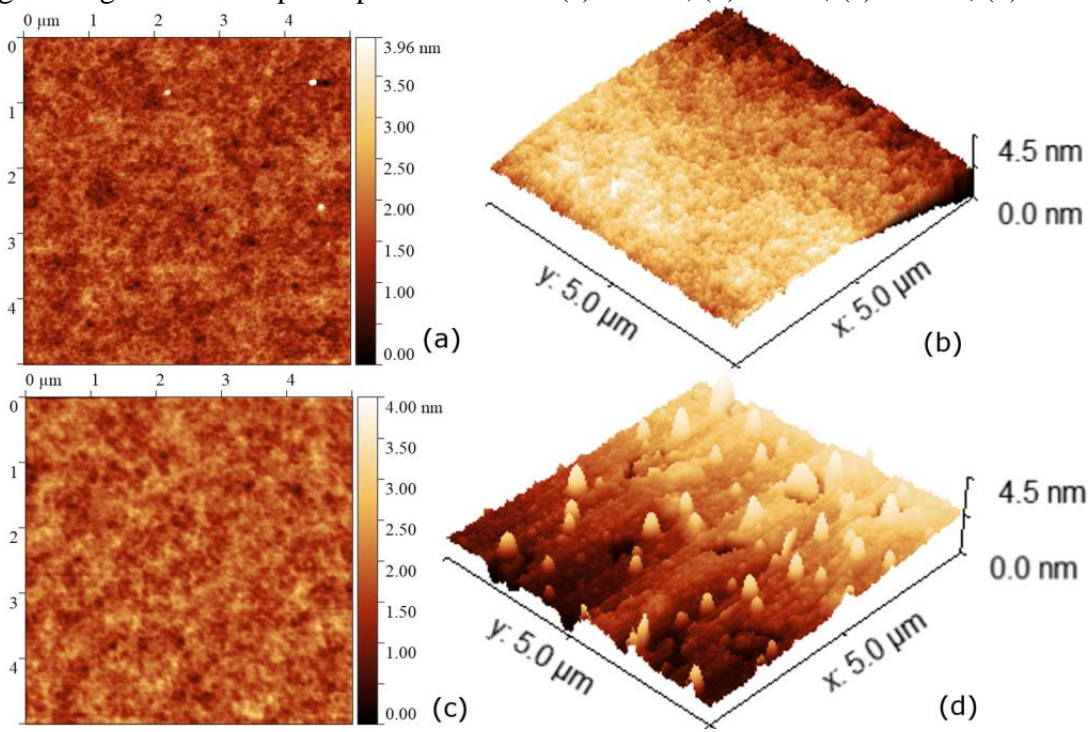

Fig. 6. AFM Topography of films: (a) 2D-MIP C, (b) 3D-MIP C, (c) 2D-NIP C, (d) 3D-NIP C
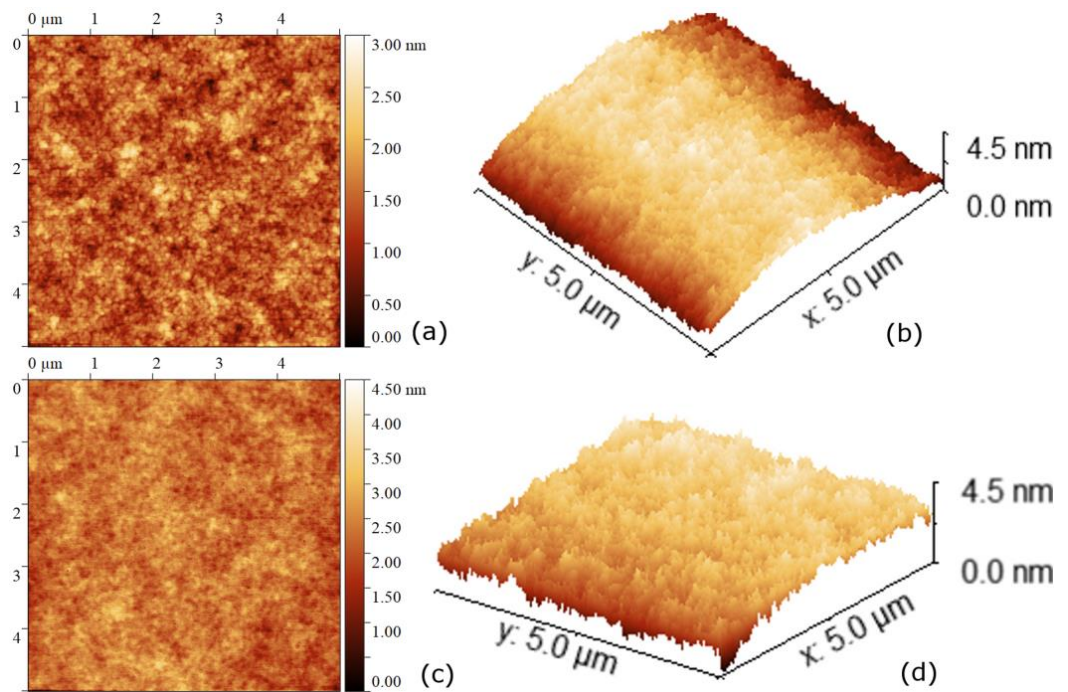

Fig. 7. AFM Topography of films: (a) 2D-MIP D, (b) 3D-MIP D, (c) 2D-NIP D, (d) 3D-NIP D

Figure 6 and figure 7 reveal the films topography investigated using atomic force microscopy in 2D and 3D scans of MIP C/NIP C pair and MIP D/NIP D pair, respectively. In both the 2D and 3D scan of control film NIP C (Figure 6c and 
d), random peaks can be observed on the surface, indicating either a non-homogenous deposition or the fact that ephedrine addition improved the films homogeneity for the following MIP C film (in Figure 6a and b), as it auto-assembles with the functional monomer. Nevertheless, at lower concentrations of precursor monomer, the imprinted and the control films, (Figure 7c and d, MIP D and NIP D, respectively) presented better thickness distributions and surface uniformity. Further on, SEM micrographs (Figure 8 a-d) were consistent with the topography assessment, revealing different surface morphologies of the MIP and NIP films compared with each other, but also compared from the thickness point of view. The surface of MIP D (Figure 8c) was more homogenous comparing to the MIP C and presented a tortuous aspect. The roughness of films (presented in Figure 9) pointed toward higher surface homogeneity of MIP films relative to their control pairs and also validates the unusual surface morphology of NIP C.

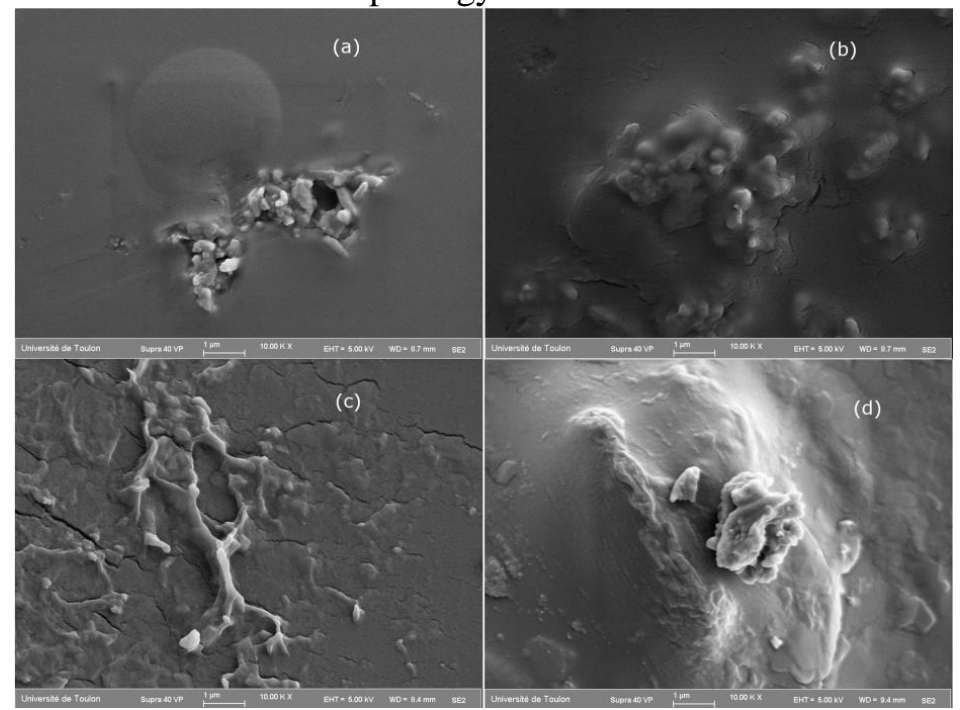

Fig. 8. SEM morphology of films at $1 \mu \mathrm{m}$ scale: (a) MIP C, (b) NIP C, (c) MIP D, (d) NIP D
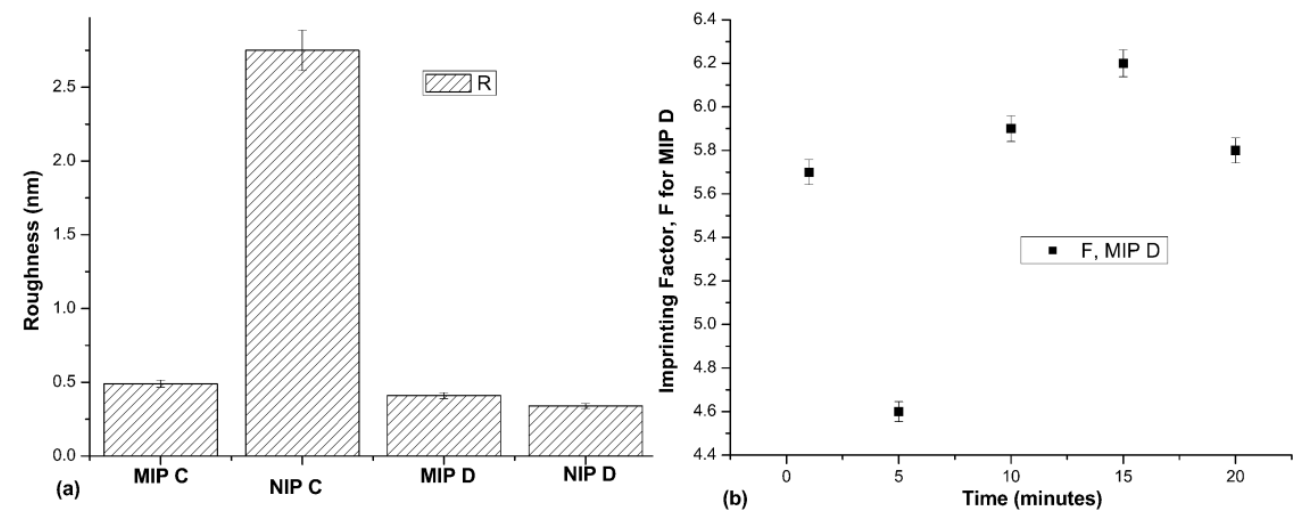

Fig. 9. Roughness of MIP C /NIP C and MIP D/NIP D pairs determined by AFM (a) and variation of the imprinting factor, $F$, in time, for the representative MIP D film (b)

\section{Batch Rebinding of Ephedrine}

Finally, to evaluate the binding affinity for ephedrine of the MIP relative to the NIP films, rebinding experiments were performed. After drying, the films were weighed and immersed in a feed aqueous solution of ephedrine with known concentration. For MIP C films the concentration of ephedrine increased in the supernatant in the studied time range, which can be due to a phenomenon called leaching; this means that ephedrine was not entirely extracted from the MIP C film and it was desorbed during batch rebinding tests. Therefore, determining $Q$ and $F$ for this MIP C/ NIP C pair was not possible. However, MIP D film seemed to rebind ephedrine quantitatively with high specificity relative to the reference NIP D film. The concentration of supernatants was assessed by UV-vis measurements at 1 minute, 5, 10, 15, 20 minutes after contact (in duplicate) and the specific parameters, in terms of binding capacity, $Q$ ( $\mu \mathrm{g}$ ephedrine/ $\mathrm{g}$ of film), and imprinting factor, $F$, were determined and outlined in Table 3 and Figure 9b, respectively. 
Table 3

BINDING CAPACITIES, $Q$, AND IMPRINTING FACTORS, $F$, OF MIP D AND NIP D FILMS

\begin{tabular}{|l|c|c|c|c|c|}
\hline Time & $1 \mathrm{~min}$ & $5 \mathrm{~min}$ & $10 \mathrm{~min}$ & $15 \mathrm{~min}$ & $20 \mathrm{~min}$ \\
\hline The adsorption capacity, $\boldsymbol{Q}(\boldsymbol{\mu g} / \mathbf{g})$ & 0.0234 & 0.0224 & 0.0217 & 0.0209 \\
\hline MIP D & 0.0217 & 0.0051 & 0.0038 & 0.0035 & 0.0036 \\
\hline NIP D & 0.0038 & \multicolumn{5}{l}{} \\
\hline
\end{tabular}

The difference of binding capacity from MIP D to NIP D was approximately one order of magnitude and definitely due to the molecularly imprinted cavities formed during synthesis. At the same time, the imprinting factors, $F$, attained high values between 4.6 and 6.2 (maximum attained at 15 minutes) on the studied time range (Figure 9b). Thus, confirming the efficiency of the imprinting method, in terms of strong interactions between the MIP D film and ephedrine, fast and specific recognition and binding of ephedrine [40,51]. These results are by far superior relative to other literature reports [52-54]. For instance, Tian $e t$ al. [52] reported ephedrine binding capacities of approximately $95 \mu \mathrm{g} / \mathrm{g}$ for MIP and $86 \mu \mathrm{g} / \mathrm{g}$ for NIP, which resulted in a 1.1 imprinting factor.

\section{Conclusions}

In this study, ephedrine-MIP films were obtained by air-sparing on glass supports sol-gel precursors in order to develop sensitive elements for ephedrine recognition. Structural, thermal, optical and morphological assessments were complementary, helping toward revealing and explaining the discrete modifications of the films structure that occurred during molecular imprinting. According to the batch re-binding experiments, only the imprinted thin film, MIP D was performant, attaining a 10 times higher rebinding capacity relative to the control film. The recorded imprinting factor in the first minute of contact was above 5 and increased at 6.2 after 15 minutes, reveling fast and specific adsorption of ephedrine.

Acknowledgements:The authors would like to thank to the Romanian Funding Organization UEFISCDI and the European Union, for funding the study through project RUTE No. 123/2018 BACTERIOSENS and M-ERA.NET2 No.71/2017 TANDEM.

\section{References}

1. PAL, R., MEGHARAJ, M., KIRKBRIDE, K.P., NAIDU, R., Sci. Total Enviro, 463-464, 2013, p.1079-1092.

2.***EMCDDA (European Monitoring Centre for Drugs and Drug Addiction). Annual report: the state of the drugs problem in Europe. http://www.emcdda.europa.eu/publications/annual-report/2007_en. [Accessed on November 23, 2018].

3.*** EMCDDA (European Monitoring Centre for Drugs and Drug Addiction). Annual report:the state of the drugs problem in Europe. http://www.emcdda.europa.eu/publications/annual-report/2010_en. [Accessed on November 23, 2018].

4. BALAMURRUGAN, K., GOKULAKRISHNAN, K., PRAKASAM, T., Arab. J. Chem., 9, nr.2, 2016, p. S528-S536.

5. KASPRZYK-HORDERN, B., BAKER, D.R., Environ. Sci. Technol., 46, nr.3, 2012, p.1681-1691.

6. CHIAIA, A.C., BANTA-GREEN, C., Field, J., Environ. Sci. Technol., 42, nr.23, 2008, p. 8841-8848.

7. SKINNER, H.F., Forensic Sci. Int., 48, nr.2, 1990, p.123-134.

8. MAYO, E., COXON, A., JOHNSON, C., J. Clandest. Lab. Investig. Chem. Assoc., 19, 2009, p.30-39.

9. WATSON, J., COXON, A., BOGUN, B., J. Clandest. Lab. Investig. Chem. Assoc., 25, 2015, p. 21-37.

10. VALLELLY, P., J. Clandest. Lab. Investig. Chem. Assoc., 5, nr. 2, 1995, p. 14-15.

11.***Ephedrine - https://pubchem.ncbi.nlm.nih.gov/compound/Ephedrine\#section=Experimental-Properties (accessed July 29, 2018).

12. LEE, K.M., KIM, H.J., JEONG, E.S., YOo, H.H,, KWON, O.S., JIN, C., KIM, D.H., LEE, J., Rapid Commun. Mass Spectrom., 25, nr.16, 2011, p. 2261-2267.

13. GRAY, N., MUSENGA, A., COWAN, D.A., PLUMB, R., SMITH, N.W., J.Chromatogr. A, 1218, nr. 12, 2011, p.2098-2105.

14. STRANO-ROSSI, S., LEONE, D., DE LA TORRE, X., BOTRE, F., J. Anal. Toxicol., 34, nr.4, 2010, p. $210-215$.

15. SARDELA, V.F., SARDELA, P.D., PEREIRA, H.M., AQUINO-NETO, F.R., J.Chromatogr. A, 1218, nr. 9, 2011 , p. $1266-1272$.

16.***United Nations Office on Drugs and CrimeVienna, Recommended methods for the identification and analysis of amphetamine, methamphetamine and their ring-substituted analogues in seized materials, United Nations New York, 2006, Sales No. E.06.XI.1, ISBN 92-1148208-9.

17. TOTHILL, I.E., Comput. Electron. Agric., 30, nr. 1-3, 2001, p. 205-218.

18. PARELLADA, J., NARVAEZ, A., LOPEZ, M. A., DOMINGUEZ, E., FERNANDEZ, J.J., PAVLOV, V., KATAKIS, I., Anal.Chim. Acta, 362, nr.1, 1998, p. 47-57.

19. STETTER, J.R., PENROSE, W.R., YAO, S., J., Electrochem. Soc.,150, nr.2, 2003, p. S11-S16.

20. HULANICKI, A., GLAB, S., INGMAN, F., Pure\&Appl.Chem., 63, nr. 9, 1991, p. 1247-1250.

21. ASKIM, J.R., MAHMOUDI, M., SUSLICK, K.S., Chem. Soc. Rev., 22, 2013, p. 8649-4682.

22.MÅRTENSSON, M., OLSSON, M., SEGALL, B., FRASER, A.G., WINTER, R., BRODIN, L.Å., Eur. J. .Echocardiogr., 10, nr.3, 2009, p. 389394.

23. LEE, L.H., RAJKUMAR, R., LO, L.H., WAN, C.H., ISA, D., Expert Systems with Applications, 40, nr.6, 2013 , p.1925-1934. 
24. BØIFOT, A.M., Eur. Trans.Telecommun., 5, nr.2, 1991, p. 503-510.

25. MORGALlA, M.H., METTENLEITER, H., BITZER, M., FRETSCHNER, R., GROTE, E.H., J. Med. Eng. Technol., 23 , nr.4, 1999 , p. $144-151$. 26. DYSHLYUK, A.V., VITRIK, O.B., KULCHIN, Y.N., MITSAI, E.V., CHEREPAKHIN, A.B., BRANGER, C., BRISSET, H., IORDACHE, T.V., SARBU, A., J. Light. Technol., 35, nr.24, 2017, p. 5425-5431.

27. RONDA, S., DE ESPINOSA, F.M., Adv. Appl. Ceram., 117, nr. 3, 2018, p. 177-181.

28. ZANG, K., WU, T., MENG, Q., MENG, Q., Int. J. Adv. Manuf. Technol., 94, nr. 9-12, 2018, p. 3209-3215.

29. ALIROTEH, M.S., ARBABIAN, A., IEEE Trans. Microw. Theory Tech., 66, nr. 12, 2018, p. 577-588.

30. TAKAGISHI, T., KLOTZ, I.M., Biopolymers, 11, nr. 2, 1972, p. 483-491.

31. WULFF, G., SARHAN, A., Angew. Chem. Int. Ed., 11, 1972, p. 341-342.

32. MOSBACH, K., RAMSTRÖM, O., Nat. Biotechnol., 14, 1996, p. 163-170.

33. WHITCOMBE, M.J., ALEXANDER, C., VULFSON, E.N., Trends Food Sci. Technol., 8, nr.5, 1997, p. 140-145.

34. YAN, S., FANG, Y., GAO, Z., Biosens. Bioelectron., 22, nr. 6, 2007, p. 1087-1091.

35. ALEXANDER, C., ANDERSSON, H.S., ANDERSSON, L.I., ANSELL, R.J., KIRSCH, N., NICHOLLS, I.A., O’MAHONY, J., WHITCOMBE, M.J., J. Mol. Recognit., 19, 2006, p. 106-180.

36. YE, L., MOSBACH, K., Chem. Mater., 20, nr.3, 2008, p. 859-868.

37. PILETSKA, E.V., GUERREIRO, A.R., WHITCOMBE, M.J., PILETSKY, S.A., Macromolecules, 42, nr. 14, 2009 , p. $4921-4928$.

38. POMA, A., TURNER, A.P.F., PILETSKY, S.A., Trends Biotechnol., 28, nr.12, 2010, p. 629-637.

39. POHANKA, M., Int.J.Electrochem.Sci., 12, 2017, p. 8082-8094.

40. YEMIŞ, F., ALKAN, P., YENIGÜL, B., YENIGÜL, M., Polymers and Polymer Composites, 21, nr.3, 2013, p. 145-150.

41. HOLTHOFF, E.L., BRIGHT, F.V., Anal. Chim. Acta, 594, nr. 2, 2007, p. 147-161.

42. PILETSKY, S.A., ALCOCK, S., TURNER, A.P.F., Trends Biotechnol, 19, nr.1, 2001, p. 9-12.

43. VASAPOLLO, G., DEL SOLE, R., MERGOLA, L., LAZZOI, M.R., SCARDINO, A., SCORRANO, S., MELE, G., Int.J.Mol.Sci., 12, 2011, p. 5908-5945.

44. PILETSKY, S.A., TURNER, A.P.F., Electroanalysis, 14, nr. 5, 2002, p. 317-323.

45. WRIGHT, J.D., SOMMERDIJK, N.A.J.M., Gordon and Breach Science Publishers, Amsterdam, 2001, vol.4, p. 15-31.

46. SHEA, K.J., LOY, D.A., Chem. Mater. 13, nr.10, 2001, p. 3306-3319.

47. HENCH, L.L., WEST, J.K., Chem. Rev., 90, nr.1, 1990, p. 33-72.

48. HOLTHOFF, E.L., BRIGHT, F.V., Acc. Chem. Res., 40, nr. 9, 2007, p. 756-767.

49. DUNN, B., ZINK, J.I., J. Mater. Chem., 1, 1991, p. 903-913.

50. LEV, O., Analusis, 20, 1992, p. 543-553.

51. FLOREA, A.M., SARBU, A., DONESCU, D., RADU, A.L., ZAHARIA, A., IORDACHE, T.V., J. Sol-Gel Sci. Technol., 76, nr. 3, 2015, p. 529541.

52. TIAN, S., GUO, Z., ZHANG, X., WUA, X., Anal. Methods, 5, nr. 19, 2013, p. 5179-5187.

53. LI, Y., FU, Q., ZHANG, Q., HE, L., Anal. Sci., 22, nr. 10, 2006, p. 1355-1360.

54. DONG, X., WANG, W., MA, S., SUN, H., LI, Y., GUO, J., J. Chromatogr. A, 1070, nr.1-2, 2005, p. 125-130.

$\overline{\text { Manuscript received: } 12.11 .2019}$ 